\title{
Avaliação da macrotextura do pavimento asfáltico do anel viário do município de Palmas (TO)
}

O pavimento pode ser definido com uma estrutura de múltiplas camadas semi-infinitas cuja função é transmitir os esforços causados pelo tráfego no terreno de fundação (subleito), além de proporcionar aos usuários boas condições de conforto e segurança. Sabemos que a morte no trânsito é responsável por gerar grandes despesas ao governo, desta forma, a segurança das estradas é crucial para o desenvolvimento do país. A textura superficial dos pavimentos condiciona diversos aspectos relacionados ao conforto e a segurança dos usuários sobretudo o efeito de aderência pneu/pavimento e hidroplanagem. 0 presente estudo avalia as principais características da macroestrutura do pavimento ao longo do traçado da Avenida NS-15 entre as avenidas Juscelino Kubitscheck e LO-08 e verifica se estes valores estão em concordância com as normas regulamentadoras ASTM E 965-96 e ASTM E 2380. Para tal, foram realizados os ensaios de Mancha de Areia e de Drenabilidade, de acordo os valores de referência no Brasil.

Palavras-chave: Pavimento Asfáltico; Macroestrutura; Segurança viária; Mancha de areia; Drenabilidade.

\section{Evaluation of the asphalt pavement macrotexture of the ring road of the city of Palmas (TO)}

The pavement can be defined with a semi-infinite multilayer structure whose function is to transmit the stresses caused by traffic on the foundation ground (subgrade), besides providing the users with good conditions of comfort and safety. We know that death in traffic is responsible for generating large expenses for the government, so road safety is crucial for the country's development. The surface texture of the pavements affects several aspects related to the comfort and safety of users, especially the effect of tire / pavement adhesion and hydroplaning. The present study evaluates the main characteristics of the pavement macrostructure along the NS-15 Avenue layout between Juscelino Kubitscheck and LO-08 avenues and verifies that these values are in accordance with the ASTM E 965-96 and ASTM E 2380 regulatory standards. To this end, the Sandblot and Drainability tests were performed according to the reference values in Brazil.

Keywords: Asphalt pavement; Macrostructure; Road safety; Sand stain; Drainability.

Topic: Engenharia Urbana

Reviewed anonymously in the process of blind peer.
Received: 07/10/2018

Approved: 08/11/2018
Thais Freitas Zenkner

Universidade Federal do Pará, Brasil

http://lattes.cnpq.br/2224971591044556

tfzenkner@gmail.com

Marcus Vinicius Barros Natanael

Universidade Presidente Antônio Carlos, Brasil

http://lattes.cnpq.br/2021606274741211

mtrbarros@hotmail.com

Flávio Vieira da Silva Junior

Instituto Tocantinense Presidente Antônio Carlos, Brasil

http://lattes.cnpq.br/2211436659738090

flaviovisiju@gmail.com
Referencing this:

ZENKNER, T. F.; NATANAEL, M. V. B.; SILVA JUNIOR, F. V.. Avaliação da macrotextura do pavimento asfáltico do anel viário do município de Palmas (TO). Revista Ibero-Americana de Ciências Ambientais, v.9, n.8, p.148-157, 2019. DOI: http://doi.org/10.6008/CBPC2179$\underline{6858.2018 .008 .0013}$ 


\section{INTRODUÇÃO}

É notório que, em virtude da crise que assolou o nosso país nos últimos 5 anos, os efeitos da queda drástica das vendas de veículos automotores (automóveis, caminhões e ônibus) a frota circulante praticamente estagnou (Instituto Brasileiro de Planejamento e Tributação), no ano de 2017, pouco mais de 889 mil veículos foram agregados a esta frota, um crescimento de apenas 1,37\% em relação ao ano anterior.

Em contramão a esse cenário, a cidade de Palmas tem apresentando valores positivos de crescimento, que segundo o IBGE (2017), a frota Palmense dobrou de tamanho nos últimos 10 anos, saltando de um pouco mais de 86 mil veículos para 175 mil. Paralelo a esse crescimento, as tecnologias embarcadas nesses automóveis também aumentaram, permitindo, sob este aspecto, que os veículos possam trafegar com maior segurança e transportar maior volume de carga.

Contudo, a infraestrutura rodoviária não acompanhou tal evolução (Confederação Nacional dos Transportes - Boletim da conjuntura de transportes no Brasil), segundo o documento, os aportes privados em rodovias, em 2017, foram 2,9\% menores do que os do ano anterior. Nas rodovias públicas federais, os investimentos caíram 10\%: em 2017, foram R\$ 7,98 bilhões, ante R\$ 8,86 bilhões investidos em 2016.

Assim sendo, as irregularidades superficiais dos pavimentos são responsáveis por influenciar o desempenho de um pavimento, desde o conforto ao rolamento e a segurança sob pista molhada até mesmo desgaste do sistema de suspensão e a deterioração e danificação de cargas, além de aspectos relacionados com ruído. Segundo os dados do Ministério da Saúde, morreram 662.219 pessoas de 1998 a 2015 em decorrência dos acidentes de trânsito.

Bernucci et al. (2007) entende que a macrotextura está ligada a aderência entre o pavimento asfáltico e a banda de rodagem do pneumático do veículo, principalmente para velocidade de tráfego superiores a $50 \mathrm{~km} / \mathrm{h}$ e afirma, ainda, que a macrotextura é a característica mais importante do pavimento a análise da hidroplanagem.

A macrotextura do pavimento deve apresentar um adequado potencial de drenagem da superfície, eliminando a água pelos seus microcanais, isso atrelado a má condição da superfície de rolamento das rodovias, são as principais causas que levam a perda de aderência pneu/pavimento e consequentemente a dificuldade de manter os veículos na trajetória desejada, sobretudo quando a pista está molhada. Estudo feito pelo Observatório Nacional de Segurança Viária (ONSV) indica gastos de R\$36bi por ano com acidentes de trânsito, ou seja, um total de R\$়720bi em 20 anos. Este valor representa 12\% do PIB (Produto Interno Bruto). Partindo deste contexto, esta pesquisa tem como objetivo avaliar a condição da macrotextura da avenida NS - 15 no plano diretor norte em Palmas (TO).

\section{REVISÃO TEÓRICA}

Um pavimento pode ser definido como um sistema de múltiplas camadas semi-infinitas destinado a distribuir os esforços verticais e horizontais oriundos do tráfego, proteger as camadas inferiores das 
intempéries e proporcionar aos usuários uma superfície segura e regular de maneira a permitir o deslocamento com segurança e economia (MEDINA et al., 2005, PAPAGIANNAKIS et al., 2008).

O atrito gerado entre o pneu e o pavimento é a variável que mantem o curso dos veículos na via e sofre grande influência de acordo com as condições ao qual está submetido, principalmente da chuva e do acumulo de água na superfície de rolamento, esse acúmulo, em frente ao pneu, faz com que pressões hidrodinâmicas sejam geradas na zona de contato pneu/pavimento e, dependendo do volume e da velocidade do veículo, pode ocorrer o fenômeno da hidroplanagem, que é a perda de contato entre o pneu e a superfície de rolamento.

O estado de conservação dos pneus, sobretudo a profundidade de seus sulcos, e a textura e inclinação transversal da via podem auxiliar na remoção da água superficial e aumentar o contato entre as superfícies. Segundo o DNER (1998) a experiência brasileira sobre aderência é bastante limitada, todavia ressalta que seu uso deverá ser difundido dada a importância quanto à segurança.

\section{Atrito}

O atrito entre superfícies pode ser entendido como a resultante de duas etapas. A primeira é a adesão nos pontos de contato entre as duas superfícies. O contato final entre as superfícies se estabelece nos contatos agudos (agregados expostos) com os pneumáticos. A segunda etapa surge se as irregularidades de uma das superfícies produzem deformações na outra de maneira a alterar sua forma original. Brosseaud relata a experiência francesa sobre projetos de pavimentos, onde cada uma das camadas tem função específica, a base de resistir a esforços mecânicos e o revestimento de proporcionar boas condições de conforto e segurança aos usuários.

\section{Macrotextura}

Consiste na textura superficiais do pavimento causadas pelas protuberâncias do agregado. Está diretamente ligada ao atrito; a condição do pavimento drenar a água superficial evitando a hidroplanagem; o efeito spray; o desgaste dos pneus e ao conforto sonoro. A figura 1 apresenta, esquematicamente, a representação de macro e microtextura.

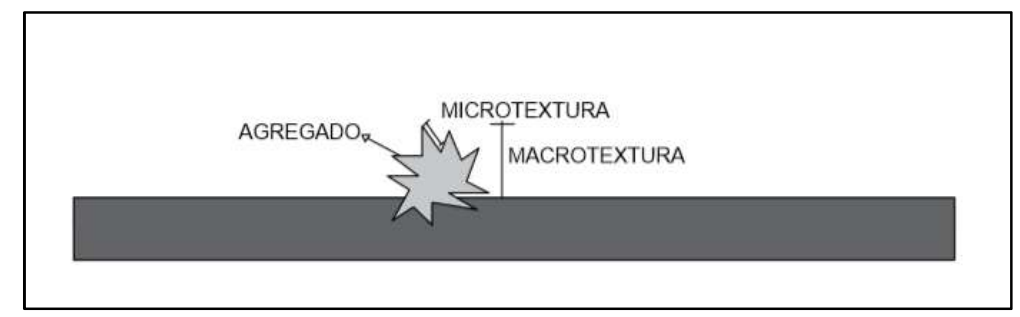

Figura 1: Representação de micro e macrotextura. Fonte: Hunter (1994).

A macrotextura tem a ver ao tamanho do agregado, à faixa granulométrica em qual se encaixa, aos vazios presentes na mistura, e a característica geométrica individual do agregado (LAY, 1998). Sendo assim, a superfície resultante depende das características de micro e macrotextura conjuntamente (PEREIRA, 2010). 
E os arranjos destas características podem converter em quatro tipos de textura: (a) rugosa e aberta; (b) rugosa e fechada; (c) polida e aberta; e (d) polida e fechada (APS, 2006).

Tabela 1: Classe de Macrotextura (Mancha de areia).

\begin{tabular}{|l|c|}
\hline \multicolumn{1}{|c|}{ Classe } & Altura média da mancha de areia (mm) \\
\hline Muito fina ou muito fechada & $\mathrm{HS} \leq 0,2$ \\
\hline Fina ou fechada & $0,20<\mathrm{HS} \leq 0,40$ \\
\hline Média & $0,40<\mathrm{HS} \leq 0,80$ \\
\hline Grosseira ou aberta & $0,80<\mathrm{HS} \leq 1,20$ \\
\hline Muito grosseira ou muito aberta & $\mathrm{HS} \leq 1,20$ \\
\hline
\end{tabular}

De acordo ao Manual de restauração de pavimentos asfálticos do Departamento Nacional de Infraestrutura e Transporte (DNIT, 2006) o ensaio mancha de areia avalia a macrotextura e determina a superfície do pavimento quanto a sua condição de escoamento da água confinada entre o pneu e o pavimento, e quantifica a densidade, ou seja, a distância média entre os agregados aflorados na superfície do revestimento. Segundo Pasquet, recomenda-se valores de adequação para a textura do revestimento, considerando a velocidade de tráfego permitida. A tabela 2 exemplifica a aplicação dos revestimentos em função da altura média de areia (HS).

Tabela 2: Aplicação do Revestimento em função do HS.

\begin{tabular}{|l|c|l|}
\hline \multicolumn{1}{|c|}{ Textura Superficial } & $\begin{array}{c}\text { Altura média da } \\
\text { mancha de areia (mm) }\end{array}$ & \multicolumn{1}{c|}{ Aplicação do revestimento } \\
\hline Muito fina ou muito fechada & $\mathrm{HS} \leq 0,2$ & Não deve ser utilizado \\
\hline Fina ou fechada & $0,20<\mathrm{HS} \leq 0,40$ & Reservado para zonas urbanas $(\mathrm{V}<80 \mathrm{~km} / \mathrm{h})$ \\
\hline Média & $0,40<\mathrm{HS} \leq 0,80$ & Indicados para vias com $80 \mathrm{~km} / \mathrm{h}<\mathrm{V} \leq 120 \mathrm{~km} / \mathrm{h}$ \\
\hline Grosseira ou aberta & $0,80<\mathrm{HS} \leq 1,20$ & Indicados para vias com $\mathrm{V}>120 \mathrm{~km} / \mathrm{h}$ \\
\hline Muito grosseira ou muito aberta & $\mathrm{HS} \leq 1,20$ & $\begin{array}{l}\text { Indicado em casos especiais (zonas de perigo constante com longos } \\
\text { trechos retos, zonas onde há uma presença constante de } \\
\text { contaminantes etc.). }\end{array}$ \\
\hline
\end{tabular}

A mancha de areia é uma medida indireta de textura que serve para determinar a média da profundidade da altura da mancha de areia (HS) em superfícies de pavimentos, este ensaio é regulamentado por duas normas, uma francesa (Mode Opératoires du Laboratorie Central dês Ponts et Chaussés - Mesure de la Profondeur 40 au Sable - Mode Opératoire RG/2 Paris - 1971) e uma americana ASTM E 965-96. Este procedimento constitui em preencher os vazios da textura da superfície do pavimento com um volume predefinido, de areia natural limpa e seca, uniforme, espalhando-a com um disco espaçador com movimentos circulares e uniformes (PEREIRA, 2010).

O ensaio de drenabilidade normatizado pela ASTM E 2830 avalia a propensão de escoamento da água superficial por entre os canais dos vazios da textura superficial e, desta forma, auxiliar na caracterização da macrotextura do revestimento. O equipamento utilizado é o drenômetro que tem as dimensões predefinidas de acordo ao Institute for Highway, Railroads and Rock Engineering (ISETH) (PEREIRA, 2010). A classificação da macrotextura também é dada pelo ensaio de drenabilidade, através do tempo de escoamento (OFT), obtidos no ensaio realizado, de acordo com a tabela 3. 
Tabela 3: Classe de macrotextura (Outflow time).

\begin{tabular}{|l|c|}
\hline \multicolumn{1}{|c|}{ CLASSE DE MACROTEXTURA (ASTM E 2380) } \\
\hline \multicolumn{1}{|c|}{ Classe } & Outflow time (s) \\
\hline Muito fina ou muito fechada & $22,59 \leq$ OFT \\
\hline Fina ou fechada & $11,98<$ OFT $\leq 22,59$ \\
\hline Média & $6,18<$ OFT $\leq 11,98$ \\
\hline Grosseira ou aberta & $4,16<$ OFT $\leq 6,18$ \\
\hline Muito grosseira ou muito aberta & $4,16>$ OFT \\
\hline
\end{tabular}

O ensaio consiste em posicionar o drenômetro sobre a superfície do pavimento, previamente molhado, e enchê-lo com água. Esta água será drenada pelos canais existentes na superfície que a borracha do orifício do drenômetro não vedar. Mede-se, então, o tempo que a água leva para ser escoada, de um volume pré-determinado (FERREIRA, 2002).

\section{METODOLOGIA}

\section{Planejamento do Experimento}

O planejamento do experimento contempla a mensuração da macrotextura, através da técnica de mancha de areia e drenabilidade no município de Palmas (TO), ao longo do traçado da Avenida NS-15, que servirá como anel viário, buscando desviar o tráfego vindo da BR-153, do centro urbano do município, entre as avenidas Juscelino Kubitscheck e LO-08. O pavimento objeto de estudo é do tipo flexível, CBUQ e de granulometria na faixa C. Os locais de escolha para realização dos ensaios foram estabelecidos de forma a abranger os pontos de maior fluxo de transporte uma vez que, nestes locais existe maior probabilidade de ocorrer desgaste superficial do pavimento.

O trecho total possui extensão de 1,94km, e para a mensuração da macrotextura foi subdividido em quatro outros trechos, foram desconsideradas as rotatórias e as pontes existentes. Foram realizados oito ensaios por trecho totalizando ao final um total de trinta e dois ensaios ao longo de todo o trajeto. A Figura 2 apresenta a alocação dos pontos nos trechos.

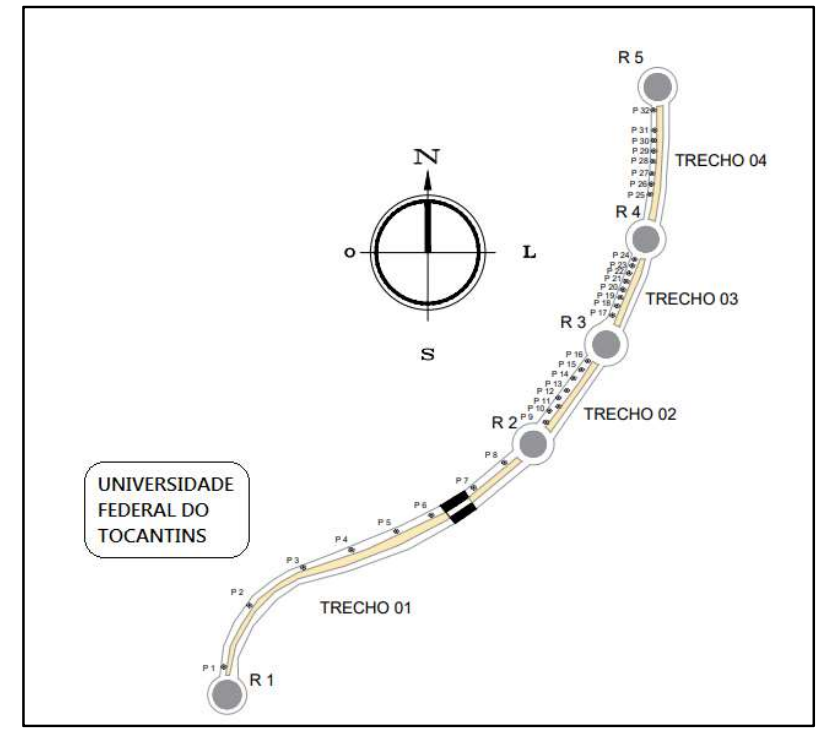

Figura 2: Alocação dos pontos na Avenida NS-15. 


\section{Ensaio de Mancha de Areia}

O processo de determinação da macrotextura foi realizado pelo método da macha de areia (ASTM E 965-96). Este consiste em espalhar a areia uniformemente limpa e seca, de volume conhecido $\left(25000 \mathrm{~mm}^{3} \pm 150 \mathrm{~mm}^{3}\right)$, com grãos que passam pela peneira $0,3 \mathrm{~mm}$ e ficam retidos na peneira com abertura 0,15 $\mathrm{mm}$, de tal forma que preencha os vazios do revestimento superficial. Com o auxílio de espalhador de madeira com revestimento de borracha, realiza-se movimentos circulares na superfície do pavimento de modo que ocorra a perfeita distribuição da areia, de forma homogênea. As figuras 3a e 3b ilustram os procedimentos básicos do ensaio. Mede-se então, o tamanho da mancha em 4 direções, calcula-se a média desses diâmetros, e, assim determina-se a altura da macrotextura: pela equação $\mathrm{HS}=\frac{4 \mathrm{~V}}{\mathrm{D}^{2} \pi}$, onde HS: Altura média da mancha de areia $(\mathrm{mm})$; V: Volume da areia $\left(25.000 \mathrm{~mm}^{3}\right)$; e D: Diâmetro médio do círculo de areia $(\mathrm{mm})$.

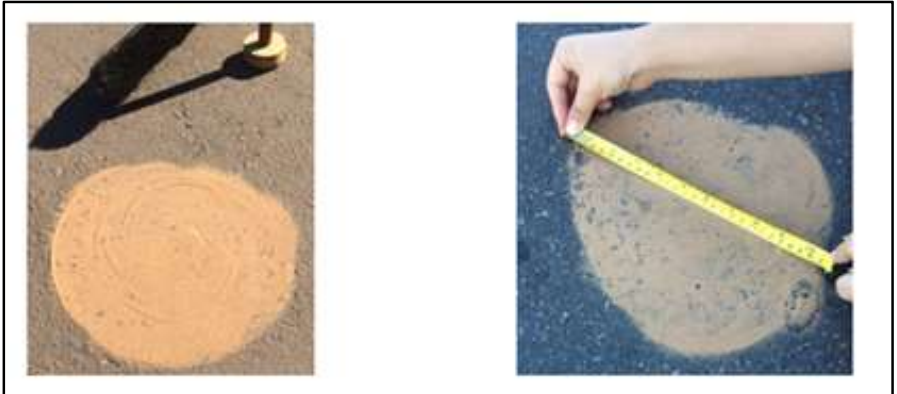

Figura 3: Mancha de areia sobre o pavimento. A) Areia espalhada sobre a superfície; B) Medida do diâmetro do círculo.

\section{Ensaio de Drenabilidade (Outflow time)}

Com a finalidade de mensurar a drenabilidade do pavimento foi realizado o ensaio de drenabilidade, onde para a sua realização utiliza-se um cilindro transparente com volume conhecido, acoplado ao fundo de placa de orifício circular, este em contato com a superfície do pavimento. Assim, o cilindro é preenchido com água e mede-se o tempo, em segundos, que a água demora para escoar, passando por duas marcas existentes no tubo, estas demarcadas para apresentar o volume conhecido (730ml). O tempo é medido de forma manual com um cronômetro. Esse tempo é conhecido como outflow time - OFT (tempo de escoamento). A figura 3 mostra a realização do ensaio.

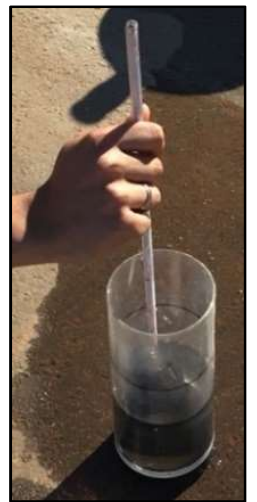

Figura 4: Ensaio em andamento. 


\section{RESULTADOS E DISCUSSÃO}

O pavimento avaliado trata-se um pavimento CBUQ com faixa granulométrica denominada faixa ' $\mathrm{C}$ ', que é a utilizada atualmente para camada de rolamento, sendo está o objeto principal deste estudo de acordo a norma do DNIT-031 de 2006, que trata de pavimentos flexíveis. Este pavimento possui granulometria com características mais finas do que as faixas ' $A$ ' e ' $B$ ' e com aspecto mais fechado, a curva granulométrica é contínua e bem-graduada, proporcionando um esqueleto mineral com poucos vazios, tornando a rodagem mais confortável sob o aspecto do ruído, em contrapartida é a que apresenta maior resistência a drenabilidade e com o coeficiente de atrito menor em relação às demais misturas de concreto asfáltico betuminoso a quente.

Os dados obtidos através do ensaio de mancha de areia apresentam quatro medidas distintas do diâmetro da mancha, com direções alternadas, permitindo calcular a altura da mancha de areia (HS) dos pontos em que foi executado o ensaio em campo. Após a resultante da altura da mancha de areia, esta obtida pelo ensaio, foi classificada a macrotextura conforme a norma da ASTM E 965-96. Através de uma planilha eletrônica, foi transcrito os dados que foram levantados em campo, de tal forma que facilitasse os cálculos quanto a sua classificação. Tais dados são analisados na tabela 4.

Tabela 4: Valores da Macrotextura pelo Método da Mancha de Areia.

\begin{tabular}{|c|c|c|c|c|c|c|c|c|}
\hline & \multirow[t]{2}{*}{ PONTOS } & \multicolumn{4}{|c|}{ MEDIDAS (cm) } & \multirow[t]{2}{*}{$\varnothing$ MÉDIA (cm) } & \multirow[t]{2}{*}{ HS mm Macrotextura } & \multirow[t]{2}{*}{ TEXTURA } \\
\hline & & 1 & 2 & 3 & 4 & & & \\
\hline \multirow{8}{*}{ TRECHO 1} & 1 & 26,0 & 24,0 & 25,0 & 23,0 & 24,5 & 0,531 & MÉDIA \\
\hline & 2 & 28,0 & 24,0 & 27,0 & 23,0 & 25,5 & 0,490 & MÉDIA \\
\hline & 3 & 24,5 & 28,0 & 25,0 & 29,0 & 26,5 & 0,454 & MÉDIA \\
\hline & 4 & 27,0 & 30,0 & 29,0 & 28,0 & 28,5 & 0,392 & FINA \\
\hline & 5 & 24,0 & 25,0 & 23,0 & 23,0 & 23,5 & 0,577 & MÉDIA \\
\hline & 6 & 25,0 & 26,0 & 24,5 & 23,5 & 24,8 & 0,520 & MÉDIA \\
\hline & 7 & 23,5 & 21,0 & 23,0 & 23,0 & 23,0 & 0,602 & MÉDIA \\
\hline & 8 & 22,5 & 23,0 & 22,5 & 24,0 & 22,8 & 0,615 & MÉDIA \\
\hline \multirow{8}{*}{ TRECHO 2} & 9 & 30,0 & 29,0 & 29,0 & 28,0 & 29,0 & 0,379 & FINA \\
\hline & 10 & 27,0 & 24,0 & 26,5 & 25,0 & 25,8 & 0,480 & MÉDIA \\
\hline & 11 & 26,0 & 24,0 & 22,0 & 23,0 & 23,5 & 0,577 & MÉDIA \\
\hline & 12 & 29,0 & 28,5 & 28,0 & 27,8 & 28,3 & 0,399 & FINA \\
\hline & 13 & 26,0 & 27,5 & 28,0 & 26,5 & 27,0 & 0,437 & MÉDIA \\
\hline & 14 & 26,0 & 27,0 & 25,0 & 29,0 & 26,5 & 0,454 & MÉDIA \\
\hline & 15 & 26,0 & 26,0 & 27,0 & 25,0 & 26,0 & 0,471 & MÉDIA \\
\hline & 16 & 25,0 & 30,0 & 27,5 & 27,0 & 27,3 & 0,429 & MÉDIA \\
\hline \multirow{8}{*}{ TRECHO 3} & 17 & 27,0 & 27,5 & 23,0 & 26,0 & 26,5 & 0,454 & MÉDIA \\
\hline & 18 & 22,1 & 21,2 & 22,8 & 23,0 & 22,5 & 0,632 & MÉDIA \\
\hline & 19 & 23,5 & 25,2 & 25,3 & 23,9 & 24,6 & 0,528 & MÉDIA \\
\hline & 20 & 28,0 & 27,3 & 27,5 & 23,0 & 27,4 & 0,424 & MÉDIA \\
\hline & 21 & 26,5 & 23,2 & 26,5 & 26,3 & 26,4 & 0,457 & MÉDIA \\
\hline & 22 & 29,0 & 25,0 & 27,5 & 25,5 & 26,5 & 0,454 & MÉDIA \\
\hline & 23 & 28,5 & 22,3 & 26,5 & 26,0 & 26,3 & 0,462 & MÉDIA \\
\hline & 24 & 26,0 & 29,0 & 25,5 & 30,0 & 27,5 & 0,421 & MÉDIA \\
\hline \multirow{8}{*}{ TRECHO 4} & 25 & 24,5 & 23,0 & 25,0 & 24,0 & 24,3 & 0,542 & MÉDIA \\
\hline & 26 & 23,6 & 24,0 & 24,5 & 25,0 & 24,3 & 0,542 & MÉDIA \\
\hline & 27 & 28,3 & 23,0 & 25,0 & 24,5 & 24,8 & 0,520 & MÉDIA \\
\hline & 28 & 26,5 & 25,0 & 26,0 & 25,5 & 25,8 & 0,480 & MÉDIA \\
\hline & 29 & 29,5 & 27,0 & 28,5 & 26,5 & 27,8 & 0,414 & MÉDIA \\
\hline & 30 & 25,0 & 22,0 & 26,0 & 24,5 & 24,8 & 0,520 & MÉDIA \\
\hline & 31 & 26,5 & 26,0 & 22,0 & 25,5 & 25,8 & 0,480 & MÉDIA \\
\hline & 32 & 27,0 & 24,0 & 25,0 & 26,3 & 25,7 & 0,484 & MÉDIA \\
\hline
\end{tabular}


No trecho 1 foi observado que, em 8 pontos, apenas um deles teve textura fina, ou seja, 12,5\%. Enquanto 87,5\% possuem textura média, estes de acordo com a ASTM 965-96. Para a normativa brasileira, apenas 2 pontos neste trecho satisfez as condições de segurança do DNIT, esta que possui a condição que a altura da mancha de areia deve estar entre $0,60 \mathrm{~mm}$ e $1,20 \mathrm{~mm}$. O trecho 2, com a mesma quantidade de pontos observados, teve $25 \%$ de textura fina e $75 \%$ de textura média. Contudo, nenhum dos pontos satisfez a condição de segurança. No trecho 3, todos os 8 pontos observados tiveram $100 \%$ de textura média, e nestes apenas um ponto foi condizente a norma de segurança. 0 trecho 4 , teve todos 8 pontos observados com textura média, ou seja, 100\%. No entanto, nenhum destes pontos satisfez a condição de segurança exigida pela norma.

Partindo desse pressuposto, por se tratar da camada de rolamento enquadrada na faixa ' $\mathrm{C}$ ', os resultados são condizentes com os valores obtidos nos ensaios. Todavia, não satisfaz a norma de condição de segurança do DNIT, que possui condição de $1,20 \mathrm{~mm} \geq \mathrm{HS} \geq 0,60 \mathrm{~mm}$, uma vez que dos 32 pontos, apenas 3 destes, com 9,375\%, satisfaz a norma de segurança.

Os dados obtidos através do ensaio de drenabilidade apresentam quatro tempos distintos, uma vez que precisam ser executadas quatro vezes, para poder realizar as médias destes valores, uma vez que este será o valor do tempo de escoamento (OFT). Assim, calcula-se a drenabilidade com o volume já conhecido. A caracterização da textura foi classificada pela norma ASTM E 2380. Com o auxílio de uma planilha eletrônica, foi transcrito os dados que foram levantados em campo, para facilitar os cálculos. Estes dados são analisados na tabela 5 .

Tabela 5: Classe de Macrotextura pelo Método da Drenabilidade.

\begin{tabular}{|c|c|c|c|c|c|c|c|c|}
\hline & \multirow[t]{2}{*}{ PONTOS } & \multicolumn{4}{|c|}{ MEDIDAS (s) } & \multirow[t]{2}{*}{ OFT } & \multirow[t]{2}{*}{ DRENABILIDADE (I/s) } & \multirow[t]{2}{*}{ TEXTURA } \\
\hline & & 1 & 2 & 3 & 4 & & & \\
\hline \multirow{8}{*}{ TRECHO 1} & 1 & 23,56 & 19,66 & 21,13 & 22,52 & 21,83 & 0,033 & FINA \\
\hline & 2 & 18,22 & 16,25 & 13,22 & 14,04 & 15,15 & 0,048 & FINA \\
\hline & 3 & 24,10 & 25,59 & 20,84 & 23,16 & 23,63 & 0,031 & FINA \\
\hline & 4 & 23,19 & 23,35 & 26,78 & 25,25 & 24,30 & 0,030 & FINA \\
\hline & 5 & 13,37 & 16,50 & 14,28 & 15,25 & 14,77 & 0,049 & FINA \\
\hline & 6 & 13,78 & 13,91 & 14,01 & 14,09 & 13,96 & 0,052 & FINA \\
\hline & 7 & 15,19 & 15,06 & 14,95 & 14,22 & 15,01 & 0,049 & FINA \\
\hline & 8 & 16,63 & 17,50 & 17,35 & 17,22 & 17,29 & 0,042 & FINA \\
\hline \multirow{8}{*}{ TRECHO 2} & 9 & 24,00 & 23,92 & 21,53 & 20,98 & 22,73 & 0,032 & MUITO FINA \\
\hline & 10 & 24,53 & 26,56 & 27,41 & 26,92 & 26,74 & 0,027 & MUITO FINA \\
\hline & 11 & 11,59 & 12,69 & 15,62 & 13,54 & 13,12 & 0,056 & FINA \\
\hline & 12 & 29,85 & 32,00 & 32,81 & 31,25 & 31,63 & 0,023 & MUITO FINA \\
\hline & 13 & 13,94 & 15,79 & 17,13 & 18,78 & 16,46 & 0,044 & FINA \\
\hline & 14 & 21,94 & 23,60 & 24,96 & 24,36 & 23,98 & 0,030 & MUITO FINA \\
\hline & 15 & 29,40 & 30,04 & 29,63 & 29,31 & 29,52 & 0,025 & MUITO FINA \\
\hline & 16 & 35,06 & 35,25 & 31,78 & 32,89 & 33,98 & 0,021 & MUITO FINA \\
\hline \multirow{8}{*}{ TRECHO 3} & 17 & 27,93 & 29,28 & 27,49 & 30,15 & 28,61 & 0,026 & MUITO FINA \\
\hline & 18 & 20,56 & 21,11 & 22,02 & 22,99 & 21,57 & 0,034 & FINA \\
\hline & 19 & 19,86 & 20,90 & 21,30 & 24,20 & 21,10 & 0,035 & FINA \\
\hline & 20 & 27,33 & 21,96 & 27,68 & 27,83 & 27,51 & 0,027 & MUITO FINA \\
\hline & 21 & 16,81 & 18,61 & 18,78 & 20,28 & 18,70 & 0,039 & FINA \\
\hline & 22 & 24,53 & 24,72 & 28,82 & 28,31 & 26,52 & 0,028 & MUITO FINA \\
\hline & 23 & 21,46 & 23,28 & 25,47 & 27,66 & 24,38 & 0,030 & MUITO FINA \\
\hline & 24 & 36,85 & 36,41 & 35,25 & 37,97 & 36,63 & 0,020 & MUITO FINA \\
\hline \multirow{3}{*}{ TRECHO 4} & 25 & 24,65 & 25,68 & 26,21 & 25,98 & 25,83 & 0,028 & MUITO FINA \\
\hline & 26 & 23,54 & 24,56 & 23,87 & 25,23 & 24,22 & 0,030 & MUITO FINA \\
\hline & 27 & 28,90 & 29,65 & 28,96 & 30,12 & 29,31 & 0,025 & MUITO FINA \\
\hline
\end{tabular}


ZENKNER, T. F.; NATANAEL, M. V. B.; SILVA JUNIOR, F. V.

\begin{tabular}{|c|c|c|c|c|c|c|c|c|}
\hline & 28 & 21,21 & 23,56 & 24,12 & 25,10 & 23,84 & 0,031 \\
\cline { 2 - 8 } & 29 & 26,55 & 25,98 & 25,63 & 26,01 & 26,00 & 0,028 \\
\cline { 2 - 8 } & 30 & 21,36 & 23,48 & 22,89 & 23,04 & 22,97 & MUITO FINA \\
\cline { 2 - 8 } & 31 & 20,15 & 22,54 & 21,33 & 22,30 & 21,82 & MUITO FINA \\
\cline { 2 - 7 } & 32 & 24,89 & 26,24 & 24,44 & 25,65 & 25,27 & FINA & 0,033 \\
\hline
\end{tabular}

No trecho 1 , foi observado que em 8 pontos, todos estes tiverem textura fina, ou seja, $100 \%$. 0 trecho 2 , com a mesma quantidade de pontos observados, teve $75 \%$ de textura muito fina e $25 \%$ de textura fina. No trecho 3, dos 8 pontos observados, 37,5\% tiveram uma textura muito fina e 62,5\% textura fina. 0 trecho 4 , teve apenas $12,5 \%$ com textura muito fina e os outros $87,5 \%$ com textura fina. Assim, com os valores de OFT, as características da estrutura estão variando entre fina e muito fina, uma vez que $43,75 \%$ dos 32 pontos tiveram textura fina e os outros $56,25 \%$ caracterizou com textura muito fina. Assim, essas macrotexturas está condizendo a granulometria, que quanto mais lisa for à estrutura a duração do escoamento será maior.

\section{CONCLUSÕES}

Esse trabalho avaliou a macrotextura do pavimento asfáltico de um trecho da avenida NS-15 do plano diretor norte, da cidade de Palmas (TO), com o objetivo de estudar a camada superficial e avaliar as condições de segurança proporcionada aos usuários da via. Realizou-se o ensaio de mancha de areia, uma vez que possui uma metodologia simples e de fácil manuseio de seu equipamento. Os dados obtidos por meio deste ensaio facilitaram a classificação da macrotextura do pavimento avaliado.

Os resultados obtidos demonstram a atual condição da camada superficial do revestimento asfáltico da avenida, que comprovou um valor médio de macrotextura baixo com a altura média da mancha de areia (HS) entre 0,4 a 0,6. Conforme a norma ASTM, esses valores possuem textura superficial média e indicada para vias com velocidade entre $80 \mathrm{~km} / \mathrm{h}$ a $120 \mathrm{~km} / \mathrm{h}$. Todavia, a avenida está localizada numa zona urbana, admitindo uma velocidade de até $80 \mathrm{~km} / \mathrm{h}$. Assim, esses valores não atendem a norma 112/2009 - ES do DNIT e nem do Manual de Restauração de Pavimentos Asfálticos (DNIT, 2006). Assim, o pavimento encontra-se fora dos padrões de segurança.

\section{REFERÊNCIAS}

APS, M.. Classificação da Aderência Pneu-Pavimento pelo Índice Combinado IFI: International Friction Index para Revestimentos Asfálticos. Tese (Doutorado) - Universidade de São Paulo, São Paulo, 2006.

BROSSEAUD, Y.. Propriedades das superfícies dos pavimentos em relação à segurança e ao conforto dos usuários. In: ENCONTRO DO ASFALTO, 18. Anais. Rio de Janeiro: 2006.

DNER. Departamento Nacional de Estradas de Rodagem. Manual de Reabilitação de Pavimentos Asfálticos. Rio de Janeiro: INPR, 1998.

DNIT. Departamento Nacional de Infraestrutura de Transportes. Pavimentos flexíveis: Concreto asfáltico: Especificação de serviço. Rio de Janeiro: INPR, 2006.
FERREIRA, P. N.. Avaliação da Macrotextura de Trechos Pavimentados de Rodovias Estaduais Situadas na Região Insular do Município de Florianópolis. Dissertação (Mestrado) - Universidade Federal de Santa Catarina, Florianópolis, 2002.

HUNTER, R. N.. Bituminous mixtures in road construction. London: Thomas Telford, 1994.

LAY, J. B. C.. Friction and Surface Texture Characterization of 14 Pavement Test Sections in Greenville. Raleigh: Transportation Research Record, 1998. DOI: http://doi.org/10.3141/1639-17.1998

MEDINA, J.; MOTTA, L. M. G.. Mecânica dos Pavimentos. Rio de Janeiro: EDUFRJ, 2005. 
PAPAgIANNAKIS, A. T.; MASSAD, E. A.. Pavement design and materials. Hoboken: John Wiley \& Sons, 2008.

PEREIRA, C. A.. Análise da Aderência Pneu-Pavimento em Rodovias dos Estados de Pernambuco e da Paraíba com
Elevado índice de Acidentes. Tese (Doutorado) Universidade Federal de Pernambuco, Recife, 2010.

PEREIRA, C. A.. Análise de correlações existentes entre as medidas de aderência pneu-pavimento avaliadas em campo e em laboratório. Transportes, v.20, n.4, 2012.

A CBPC - Companhia Brasileira de Produção Científica (CNPJ: 11.221.422/0001-03) detém os direitos materiais desta publicação. Os direitos referem-se à publicação do trabalho em qualquer parte do mundo, incluindo os direitos às renovações, expansões e disseminações da contribuição, bem como outros direitos subsidiários. Todos os trabalhos publicados eletronicamente poderão posteriormente ser publicados em coletâneas impressas sob coordenação da Sustenere Publishing, da Companhia Brasileira de Produção Científica e seus parceiros autorizados. Os (as) autores (as) preservam os direitos autorais, mas não têm permissão para a publicação da contribuição em outro meio, impresso ou digital, em português ou em tradução. 